EXTENDED REPORT

\title{
Association of polymorphism in the transforming growth factor $\beta 1$ gene with disease outcome and mortality in rheumatoid arthritis
}

\author{
D L Mattey, N Nixon, P T Dawes, J Kerr
}

See end of article for authors' affiliations

Correspondence to: Dr D L Mattey,

Staffordshire

Rheumatology Centre,

University Hospital of

North Staffordshire, The

Haywood, High Lane,

Burslem, Stoke-on-Trent

Staffordshire, ST6 7AG

UK; d.I.mattey@keele.ac.

uk

Accepted 2 January 2005

Published Online first

4 February 2005

Objective: To investigate whether polymorphism in the transforming growth factor $\beta 1$ (TGF $\beta 1$ ) gene is associated with disease outcome in rheumatoid arthritis.

Methods: 208 patients with established rheumatoid arthritis were genotyped for the TGF $\beta 1$ T869C polymorphism using an amplification refractory mutation system-polymerase chain reaction (ARMS-PCR) method. Disease severity was assessed by measuring radiographic damage by Larsen score and functional outcome by the health assessment questionnaire (HAQ). Patients were tracked on the NHS central register for notification of death, and the relation between TGF $\beta 1$ polymorphism and mortality was analysed using Cox proportional hazards regression.

Results: Patients carrying a TGF $\beta 1$ T allele had a higher mean HAQ score than those without this allele $(1.60 \vee 1.22, p=0.04)$. The Tallele was also associated with higher five year mean area under the curve (MAUC) erythrocyte sedimentation rate (ESR), and nodular disease. Larsen score was higher in patients with the $\Pi$ genotype compared with CC + CT genotypes, although this was not significant after correction for disease duration. There was a trend of increasing mortality risk with $\mathrm{T}$ allele dose after adjustment for age, sex, and disease duration (hazard ratio $=1.6$ (95\% confidence interval, 1.1 to 2.4$), p=0.01$ ).

Conclusions: TGF $\beta 1$ T869C gene polymorphism is associated with disease outcome in rheumatoid arthritis. Carriage of the T allele (putatively associated with decreased TGF $\beta 1$ production) was associated with increased inflammatory activity and poor functional outcome, while increasing $T$ allele dose was associated with worse survival.

$\mathrm{T}$ he severity and long term outcome of rheumatoid arthritis have been related to various genetic factors. Although many studies have shown that polymorphism in the HLA-DRBl gene encoding a common amino acid sequence (the shared epitope) ${ }^{1}$ is associated with measures of disease severity, recent studies have suggested that polymorphisms at other gene loci may have an impact on the progression and severity of rheumatoid arthritis.. ${ }^{2-7}$ Several cytokine genes have been considered as likely candidates for influencing disease susceptibility or severity, and various associations with cytokine gene polymorphisms have been found..$^{8-12}$

Recently, a study on a Japanese population of patients with rheumatoid arthritis suggested that polymorphism in the signal sequence at position +869 (T869C) of the transforming growth factor $\beta 1$ (TGF $\beta 1$ ) gene may be associated with increased risk of rheumatoid arthritis. ${ }^{13}$ However, a small study on a prospective cohort of white patients in New Zealand failed to find any association of the T869C polymorphism with rheumatoid arthritis prevalence or severity at two years. ${ }^{14}$

TGF $\beta$ has been considered an important modulator of the immune response in rheumatoid arthritis, and can have both pro- and anti-inflammatory effects. TGF $\beta$ exists as three isoforms-TGF $\beta 1$, TGF $\beta 2$, and TGF $\beta 3$ - and has a broad range of biological functions including wound healing, fibrosis, immune suppression, and angiogenesis. It has chemotactic properties and may stimulate cells to produce cytokines such as interleukin (IL) 1, IL6, and tumour necrosis factor $\alpha(\mathrm{TNF} \alpha)$ at sites of inflammation.

TGF $\beta$ is also a local regulator of bone metabolism, acting downstream of oestrogen and in concert with vitamin D. Enhanced expression of TGF $\beta$ has been found in synovial effusions and synovium of patients with rheumatoid arthritis. ${ }^{15-17}$

The concentration of TGF $\beta 1$ in plasma has been correlated with the development of several diseases, including atherosclerosis, bone diseases, and certain forms of cancer. ${ }^{18}$ As the level of circulating TGF $\beta 1$ appears to be under genetic control it is possible that predisposition to these diseases may be associated with particular alleles at the TGFBl locus. ${ }^{19}$ Various polymorphisms have been demonstrated in the TGF $\beta$ gene, and recent studies have shown associations with several diseases. ${ }^{20-26}$ Some of these studies have reported that the $\mathrm{T}$ allele of the T869C polymorphism is associated with lower production of TGF $\beta 1,20232427$ although an association with higher production has also been reported. ${ }^{28}{ }^{29}$

As the only previous study on the association of the T869C TGF $\beta 1$ polymorphism with rheumatoid arthritis severity was carried out on patients with early disease, ${ }^{14}$ we investigated whether this polymorphism was associated with long term outcome in a population of white patients with established disease. We also explored the association of TGF $\beta 1$ polymorphism with mortality in this group of patients.

\section{METHODS}

\section{Study population}

We studied 208 patients with long term rheumatoid arthritis (disease duration 5 to 25 years) (table 1). This was a historical cohort recruited between 1994 and 1998 in a clinic

Abbreviations: ARMS-PCR, amplification refractory mutation systempolymerase chain reaction; $B M D$, bone mineral density; $H A Q$, health assessment questionnaire; MAUC, mean area under the curve; NHSCR, National Health Service central register; ONS, Office for National Statistics; TGF, transforming growth factor 
established to monitor the effects of disease modifying antirheumatic drugs. All patients were northern European white residents in north Staffordshire and satisfied the 1987 American College of Rheumatology diagnostic criteria. ${ }^{30}$ Treatment was given as clinically indicated. Eighty nine per cent of patients were being treated with one or more disease modifying antirheumatic drugs including hydroxychloroquine, sulfasalazine, gold, or methotrexate. Fewer than 5\% of patients were being treated with corticosteroids.

Ethics permission for the study was obtained from the North Staffordshire research ethics committee.

\section{Disease outcome}

Joint damage was assessed at the time of inclusion in the study by two experienced observers scoring $x$ rays of the hands and feet using the standard radiographs of Larsen. ${ }^{31}$ The majority (more than 90\%) of the patients had erosions, with Larsen scores ranging between 22 and 205 (maximum possible, 210). Larsen scores were obtained on 173 of the 208 patients. Functional assessment was carried out using the health assessment questionnaire (HAQ). ${ }^{32}$ The presence or absence of subcutaneous nodules was recorded during physical examination of each patient at the time of recruitment. Time integrated measures of disease activity were determined from five year mean area under the curve (MAUC) levels of erythrocyte sedimentation rate (ESR) and $C$ reactive protein measured before inclusion in the study. The MAUC levels were calculated from measurements taken at approximately six monthly intervals.

\section{Survival follow up}

All patients in the study were NHS patients registered on the NHS central register (NHSCR), a computed registry of the records of all NHS patients. Access to this registry is obtained through the Office for National Statistics (ONS, General Register Office, Southport, UK). All patients in this study were tracked on the NHSCR, and notification of patient deaths was obtained from the ONS. Causes of death were coded by the ONS, using the International Classification of Diseases, ninth revision (ICD-9).

\section{TGF $\beta 1$ genotyping}

Genomic DNA was extracted from blood samples collected in EDTA using a DNAce Megablood kit as directed by the manufacturer (Bioline, London, UK). Laboratory personnel were blinded to the clinical characteristics of the donors and the hypothesis being investigated. Samples were genotyped for the TGF $\beta 1$ T869C polymorphism using an amplification refractory mutation system-polymerase chain reaction (ARMS-PCR) method with the use of primers described previously by Perrey et al. ${ }^{33}$ Amplification of a 241 base pair (bp) fragment was carried out using the following primer sequences: generic primer (sense): 5'-TCCGTGGGATACTGA GACAC-3'; primer C (antisense): 5'-GCAGCGGTAGCAGCAG CG-3'; primer $\mathrm{T}$ (antisense): 5'-AGCAGCGGTAGCAGCAG CA- $3^{\prime}$. The specific primer mix consisted of $10 \mu \mathrm{M}$ generic

\begin{tabular}{lc} 
Table 1 Characteristics of the study patients \\
\hline Male:female (n) & $93: 115$ \\
Age (years) & $60.0(25 \text { to } 89)^{*}$ \\
Age at onset (years) & $49.2(18 \text { to } 82)^{*}$ \\
Disease duration (years) & $10.0(5 \text { to } 25)^{*}$ \\
RF positive & $66.9 \%$ \\
Erosions & $92.8 \%$ \\
Nodules & $19.8 \%$ \\
\hline *Median (range). & \\
RF, rheumatoid factor.
\end{tabular}

primer and $10 \mu \mathrm{M}$ of one of the two allele specific primers. Two internal control primers amplifying a human growth hormone sequence were used to confirm successful PCR amplification. The reaction mixtures and conditions were as described previously. ${ }^{33}$ All amplification reactions were undertaken in a Flexigene thermal cycler (Techne (Cambridge) Limited, Cambridge, UK) using a 96 well heating block. Amplified products were visualised by electrophoresis on $2 \%$ agarose gels containing ethidium bromide $(0.5 \mathrm{mg} / \mathrm{ml})$.

\section{Statistical methods}

Analysis of TGF $\beta 1$ T869C allele and genotype frequencies showed that they were in Hardy-Weinberg equilibrium. The association of genotypes with normally distributed outcome measures (Larsen score) was assessed using analysis of covariance (ANCOVA) with disease duration as a covariate. Association between genotypes and non-parametric data such as HAQ, MAUC, ESR, and $\mathrm{C}$ reactive protein was assessed using Kruskal-Wallis one way analysis of variance (ANOVA) on ranks. Where appropriate, adjustment for potential multiple testing errors was carried out, either by Bonferroni correction for normally distributed data or by the Kruskal-Wallis $z$ value test for non-parametric data.

The association of TGF $\beta 1$ genotype with mortality was assessed in a Cox proportional hazard regression analysis adjusted for age, sex, and disease duration. The time intervals for those patients who were alive at the end of the study period and those who were lost to follow up were censored. The censoring date for the present analysis was 31 December 2003. Kaplan-Meier curves were constructed to illustrate the survival in patients with different TGF $\beta 1$ genotypes. The curves were compared using the log rank significance tests. All data were analysed using Number Cruncher Statistical System (NCSS) (version 5.01) and Graphpad Prism software (version 1.03).

\section{RESULTS}

\section{TGF 1 T $869 \mathrm{C}$ polymorphism and disease outcome}

These results are summarised in table 2. Analysis of covariance with inclusion of disease duration as a covariate showed no overall significant difference between TGF $\beta 1$ genotypes for mean Larsen score $(p=0.09)$, although there was a trend towards higher scores with increasing $\mathrm{T}$ allele number. Comparison of the TT genotype with the remainder (CC + CT genotypes) revealed a higher Larsen score in the TGFBl TT genotype $(\mathrm{p}=0.04)$, although significance was lost after correction for disease duration $(p=0.07)$. In the case of the HAQ score, patients with a CT genotype had a significantly higher score than those with a CC genotype ( $p=0.02$, after correction for multiple comparisons). However, there was essentially no difference between patients with a CT and TT genotype, and overall those with a T allele (CT or TT) had a significantly higher HAQ score than those lacking the $\mathrm{T}$ allele $(\mathrm{p}=0.02)$. This remained significant $(p=0.04)$ when corrected for disease duration using ANCOVA.

\section{Association of TGF $\beta 1$ polymorphism with time integrated disease activity}

Previous studies have shown that time integrated measures of disease activity are associated with more severe radiographic and functional outcome. ${ }^{34}{ }^{35}$ We therefore examined the association of the TGF $\beta 1$ polymorphism with five year MAUC levels of ESR and $C$ reactive protein (table 3 ). No significant differences were found between individual TGF $\beta$ genotypes for five year MAUC ESR or $\mathrm{C}$ reactive protein. However, a weakly significant difference in MAUC ESR levels was found between patients carrying a $\mathrm{T}$ allele and the 
Table 2 Association between TGF $\beta 1$ T869C genotypes and measures of disease outcome in rheumatoid arthritis

\begin{tabular}{lllll}
\hline TGFß1 genotype & $\mathbf{n}(\%)$ & Larsen score & $\mathbf{n}(\%)$ & HAQ score \\
\hline $\mathrm{CC}$ & $28(16.2)$ & $81.1(47.8)$ & $30(14.4)$ & $1.22(0.9)$ \\
$\mathrm{CT}$ & $80(46.2)$ & $87.7(48.0)$ & $103(49.5)$ & $1.65(0.8)$ \\
$\Pi$ & $65(37.6)$ & $101.1(43.4)$ & $75(36.1)$ & $1.56(0.8)$ \\
\hline
\end{tabular}

Values are $\mathrm{n}(\%)$ or mean (SD).

Differences in Larsen score between genotypes were analysed by analysis of covariance (ANCOVA) with inclusion of disease duration as a covariate. No significant difference was found between individual TGF $\beta 1$ genotypes $(p=0.09)$. Comparison of the $\Pi$ genotype with the remainder $(C C+C T)$ showed a higher Larsen score in the former $(p=0.04)$, but significance was lost after correction for disease duration $(p=0.07)$. The mean HAQ score was significantly higher in patients with a CT genotype than those with $C C(p=0.02$, after correction for multiple comparisons). No significant difference was found between patients with a CT and TT genotype, and overall, those patients carrying a T allele had a significantly higher $\mathrm{HAQ}$ score than those lacking this allele $(p=0.04$, after correction for disease duration)

$H A Q$, health assessment questionnaire.

remainder $(30.6 v 24.3, \mathrm{p}=0.05)$. Similarly the $\mathrm{T}$ allele was associated with a higher MAUC C reactive protein level, although this was non-significant $(\mathrm{p}=0.09)$.

\section{Association of TGF $\beta 1$ polymorphism with nodular disease}

In addition to worse radiographic and functional outcome, patients with severe rheumatoid arthritis are more likely to develop extra-articular features such as subcutaneous nodules. We examined whether the TGFBl $\mathrm{T}$ allele was associated with the development of nodular disease in these patients. Comparison between individuals with and without the $\mathrm{T}$ allele showed a significant difference in the frequency of nodular disease. Thus $38 / 171$ patients $(22.2 \%)$ with a T allele had nodules compared with $1 / 26$ patients $(3.8 \%)$ without a $\mathrm{T}$ allele (odds ratio $(\mathrm{OR})=5.1$ (95\% confidence interval (CI), 1.02 to 151.8$) ; \mathrm{p}=0.025)$.

\section{Association of TGF $\beta 1$ polymorphism with mortality} By 31 December 2003, 58 patients (27.9\%) had died (34 male, 24 female). The most common cause of death was cardiovascular disease $(48.3 \%)$, followed by malignancy $(24.1 \%)$. The relation of the TGF $\beta 1$ T869C polymorphism with mortality was initially examined in a multivariate Cox proportional hazards regression model which included age at entry into the study, disease duration at entry, and sex. In this model the TGF $\beta 1$ genotypes were ordered as categorical variables according to $\mathrm{T}$ allele number (that is, $0,1,2$ ). The analysis showed a significant trend of increasing mortality risk with $\mathrm{T}$ allele dose (hazard ratio $(\mathrm{HR})=1.6$ (95\% CI, 1.1 to 2.4$) ; \mathrm{p}=0.01$ ) which was independent of age and male sex. In additional analyses we also included rheumatoid

Table 3 Association between TGF $\beta 1$ T869C genotypes and time-integrated measures of disease activity rheumatoid arthritis

\begin{tabular}{llll}
\hline $\begin{array}{l}\text { TGFß1 } \\
\text { genotype }\end{array}$ & $\mathbf{n}$ & MAUC ESR $(\mathbf{m m} / \mathbf{h})$ & MAUC CRP $(\mathbf{m g} / \mathbf{l})$ \\
\hline CC & 25 & $24.3(18.2)$ & $16.2(16.7)$ \\
CT & 76 & $30.7(18.1)$ & $20.2(18.2)$ \\
$\Pi$ & 57 & $30.8(16.9)$ & $23.8(20.6)$ \\
\hline
\end{tabular}

Differences between genotypes were analysed by Kruskal-Wallis one way analysis of variance. No significant differences were found between individual TGF $\beta 1$ genotypes for five year mean area under the curve (MAUC) erythrocyte sedimentation rate (ESR) or C-reactive protein (CRP) levels. However, comparison between patients with a $\mathrm{T}$ allele and the remainder showed a weak significant difference in MAUC ESR levels $(p=0.05)$. A similar non-significant trend was seen with MAUC CRP levels $(p=0.09)$. factor status, presence or absence of nodules, and MAUC ESR. Although MAUC C reactive protein and MAUC ESR were both associated with mortality when analysed separately, only the latter was shown to be significantly associated $(\mathrm{p}<0.0001)$ in a model containing both MAUC ESR and $C$ reactive protein. The trend of increasing risk with $\mathrm{T}$ allele number remained significant in a model containing MAUC ESR, rheumatoid factor, and nodules, and in a stepwise model the strongest predictors of death were MAUC ESR, age, male sex, and TGF $\beta 1$ genotype (table 4). Construction of a Kaplan-Meier survival probability curve showed that poorer survival over a 10 year follow up period was particularly associated with individuals carrying the TGF $\beta 1$ TT genotype (fig l).

Examination of the causes of death showed that the TGF $\beta 1$ TT genotype was more common in patients who had died from malignancy (12 solid tumours, two haematological) than had died from other causes, although this was not significant $(64.3 \% \vee 33.6 \%, \mathrm{OR}=2.7$ (95\% CI, 0.7 to 12.0$)$; $\mathrm{p}=0.1)$. In a Cox proportional hazards regression model the TGF $\beta 1$ TT genotype was associated with an increased risk of cancer related mortality $(\mathrm{HR}=3.5(95 \% \mathrm{CI}, 1.2$ to 10.6$)$; $\mathrm{p}=0.02$ ), after adjustment for age, sex, and disease duration.

\section{DISCUSSION}

Our data indicate that the $\mathrm{T}$ allele of the T869C polymorphism in the TGF $\beta 1$ gene is associated with certain aspects of long term disease outcome in rheumatoid arthritis. These include increased time integrated inflammatory activity, worse functional outcome, and increased frequency of rheumatoid nodules. In addition, there was a significant trend towards poorer survival with increasing $\mathrm{T}$ allele dose. Structural damage appeared to be greater in patients with a

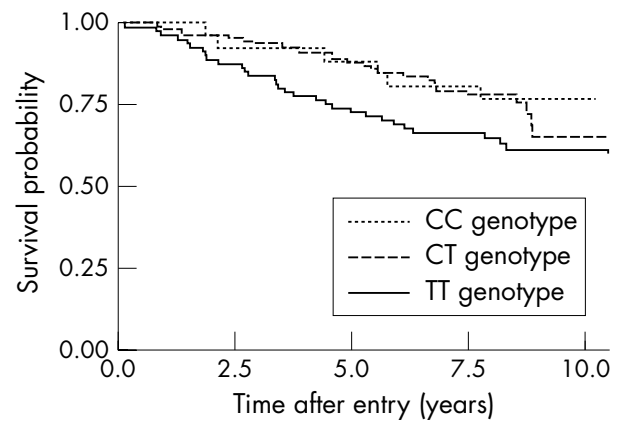

Figure 1 Kaplan-Meier survival probability curve illustrating the poorer survival of individuals with the TGF $\beta 1$ Tा genotype compared with those carrying $\mathrm{CC}$ or $\mathrm{CT}$ genotypes. 
Table 4 Stepwise Cox proportional hazards model showing independent predictors of mortality in patients with established rheumatoid arthritis

\begin{tabular}{llll}
\hline Step and variable & Regression coefficient & Hazard ratio $(95 \% \mathrm{Cl})$ & p Value \\
\hline 1. MAUC ESR & 0.026 & $1.03 / \mathrm{mm} / \mathrm{h}(1.01$ to 1.04$)$ & $<0.0001$ \\
2. Age & 0.055 & $1.06 /$ year $(1.02$ to 1.09$)$ & 0.007 \\
3. Male sex & 0.777 & $2.2(1.2$ to 4.1$)$ & 0.003 \\
4. TGF $\beta 1$ genotype* & 0.463 & $1.6(1.02$ to 2.5$)$ & 0.04 \\
\hline *The TGF $\beta 1$ genotypes were ordered as categorical variables according to T allele number (that is, $0,1,2)$. The \\
hazard ratio shows the increased risk per unit increase in T allele number. \\
Cl, confidence interval; ESR, erythrocyte sedimentation rate; MAUC, mean area under the curve.
\end{tabular}

TT genotype, but the absence of a significant association with Larsen score after correction for disease duration did not support an association between this genotype and structural severity.

Our results are in contrast to those of a recent prospective study on a smaller number of white patients $(n=117)$ with early disease. ${ }^{14}$ That study found no association with the prevalence or severity of rheumatoid arthritis. However, patients were examined only up to two years of disease duration, so it is possible that the effect of this polymorphism becomes evident at a later stage of disease.

Inconsistent findings have also been reported on the association of the T869C polymorphism with other diseases. An association with osteoporosis has been found in Japanese women ${ }^{27}$ and in elderly white Australian women. ${ }^{36}$ However, in the Japanese population the T allele was associated with lower bone mineral density (BMD) and increased vertebral fractures, while in the Australian patients the $\mathrm{C}$ allele was associated with lower BMD and an increase in prevalent fractures. In another study of German postmenopausal women the CC genotype was associated with lower BMD and greater bone loss. ${ }^{28}$ In contrast to these reports, studies in a Chinese population, and on white women in the USA, failed to find an association. ${ }^{37} 38$

Reports on the association of the T869C polymorphism with TGF $\beta 1$ production have also been inconsistent. Some studies have shown that the $\mathrm{T}$ allele of the T869C polymorphism is associated with lower production of TGF $\beta 1,20232427$ but the converse has also been found. ${ }^{28} 29$ The results of our study suggest that rheumatoid patients carrying a $\mathrm{T}$ allele may have increased inflammatory activity over the long term. The poor outcome and earlier mortality in these patients may possibly be explained by reduced production of TGFBl leading to worse control of inflammation. Such an effect would be cumulative so may only become evident in long term outcome studies such as this. We and others have shown previously that time integrated measures of disease activity are associated with more severe radiographic and functional outcome, and that a high level of sustained inflammation is predictive of earlier mortality in rheumatoid arthritis. ${ }^{34} 3539$

It is noteworthy that $\mathrm{T}$ allele dose of the TGF $\beta 1 \mathrm{~T} 869 \mathrm{C}$ polymorphism was associated with poorer survival in this rheumatoid population. It needs to be stressed that this particular patient group already had well developed disease of five years' duration or more, so the influence of this polymorphism on the mortality of rheumatoid arthritis patients within five years of development was not investigated. However, our data indicate that in patients with established disease the carriage of a $\mathrm{T}$ allele increases the risk of death and that this increases with $\mathrm{T}$ allele dose.

In a previous Japanese study on myocardial infarction, it was suggested that the $\mathrm{T}$ allele was a risk factor for susceptibility to myocardial infarcts in middle aged Japanese men. ${ }^{20}$ However, the data on TGF $\beta 1$ polymorphism and ischaemic heart disease are controversial, with the majority of studies showing no association. Although ischaemic heart disease is common in rheumatoid patients, and myocardial infarction is a frequent cause of death, we found no evidence in this study for an association of the $\mathrm{T}$ allele with coronary heart disease related mortality or cardiovascular mortality in general. However we did find a possible association between homozygosity for the $\mathrm{T}$ allele and mortality from malignancy. The TT genotype was more common in patients who had died from malignant disease, and the overall likelihood of cancer related mortality was increased in patients with this particular genotype. These data need to be treated with caution because of the relatively small number of deaths from malignancy. In other studies, carriage of one or two TGF $\beta 1 \mathrm{~T}$ alleles has been associated with increased susceptibility to prostate cancer, hepatocellular carcinoma in patients with chronic hepatitis B infection, and breast cancer. ${ }^{25}{ }^{40-42}$ However, the studies on breast cancer have been inconsistent, with some showing no association. ${ }^{43}{ }^{44}$ One study on breast cancer progression showed that the CC (high producing) genotype was associated with worse survival. ${ }^{45}$

The evidence to date suggests that polymorphisms within the TGF $\beta 1$ gene may play a significant role in determining the development or severity of various diseases. Controversies over the association with particular diseases or disease features may arise partly from differences between ethnic groups, as well as from differences in the stage at which particular diseases have been examined. The results of our study suggest that the association of rheumatoid arthritis severity with the T869C polymorphism may be more evident in patients with well established disease where the manifestations of severe disease are more distinct than early in the disease course.

\section{Conclusions}

We have shown that polymorphism in codon 10 of the TGF $\beta 1$ gene may be associated with disease outcome and mortality in white patients with rheumatoid arthritis. Measures associated with poor outcome including increased long term inflammation, worse functional outcome, and nodular disease were associated with carriage of a $\mathrm{T}$ allele, which has been linked to lower production of TGF $\beta 1$ in other studies. In addition, there appears to be an association between $\mathrm{T}$ allele dose and earlier mortality. These findings suggest a role for TGF $\beta 1$ polymorphism in the long term outcome of rheumatoid arthritis, but this will need confirmation in studies on other rheumatoid arthritis populations.

\section{ACKNOWLEDGEMENTS}

We wish to thank Mrs June Fisher and Mrs Sheila Clarke (metrologists) for their help with data collection, and Professor Peter Jones (Department of Mathematics, Keele University) for statistical advice. Work supported by the Haywood Rheumatism Research and Development Foundation. 


\section{Authors' affiliations}

D L Mattey, N Nixon, P T Dawes, Staffordshire Rheumatology Centre, University Hospital of North Staffordshire, Stoke-on-Trent, Staffordshire, UK

J Kerr, Department of Microbiology, Royal Brompton Hospital, National Heart and Lung Institute, Imperial College London, London, UK

\section{REFERENCES}

1 Gregersen PK, Silver J, Winchester RJ. The shared epitope hypothesis: An approach to understanding the molecular genetics of susceptibility to rheumatoid arthritis. Arthritis Rheum 1987;30:1205-13.

2 Mattey DL, Hassell AB, Dawes PT, Jones PW, Yengi L, Alldersea J, et al. Influence of polymorphism in the manganese superoxide dismutase locus on disease outcome in rheumatoid arthritis. Evidence for interaction with glutathione S-transferase genes. Arthritis Rheum 2000;43:859-64.

3 Zapico I, Coto E, Rodriguez A, Alvarez C, Torre JC, Alvarez V. A DNA polymorphism at the $\alpha 2$ - Macroglobulin gene is associated with the severity of rheumatoid arthritis. J Rheumatol 2000;27:2308-11.

4 Constantin A, Lauwers-Cances V, Naxaux F, Abbal M, van Meerwijk J, Mazieres B, et al. Stromelysin 1 (matrix metalloproteinase 3) and HLA-DRB gene polymorphisms. Association with severity and progression of rheumatoid arthritis in a prospective study. Arthritis Rheum 2002;46:1754-62.

5 Rodriguez MR, Gonzalez-Escribano MF, Aguilar F, Valenzuela A, Garcia A Nunez-Roldan A. Association of NRAMP1 promoter gene polymorphism with the susceptibility and radiological severity of rheumatoid arthritis. Tissue Antigens 2002;59:31 1-15.

6 Brun JG, Madland TM, Vedeler CA. Immunoglobulin G fc-receptor (FcgammaR) IIA, IIIA, and IIIB polymorphisms related to disease severity in rheumatoid arthritis. J Rheumatol 2002;29:1135-40.

7 Baugh JA, Chitnis S, Donnelly SC, Monteiro J, Lin X, Plant BJ, et al. A functional promoter polymorphism in the macrophage migration inhibitory factor (MIF) gene associated with disease severity in rheumatoid arthritis. Genes Immun 2002;3:170-6.

8 van Krugten MV, Huizinga TW, Kaijzel EL, Zanelli E, Drossaers-Bakker KW, van de Linde $P$, et al. Association of the TNF +489 polymorphism with susceptibility and radiographic damage in rheumatoid arthritis. Genes Immun 1999;1:91-6.

9 Cantagrel A, Navaux F, Loubet-Lescoulie P, Nourhashemi F, Enault G, Abbal $M$, et al. Interleukin-1 beta, interleukin-1 receptor antagonist, interleukin-4, and interleukin-10 gene polymorphisms: relationship to occurrence and severity of rheumatoid arthritis. Arthritis Rheum 1999:42:1093-100.

10 Zapico I, Coto E, Rodriguez A, Alvarez C, Torre JC, Alvarez V. CCR5 (chemokine receptor-5) DNA-polymorphism influences the severity of rheumatoid arthritis. Genes Immun 2001;1:288-9.

11 Buchs N, di Giovine FS, Silvestri T, Vannier E, Duff GW, Miossec P. IL-1B and IL-1Ra gene polymorphisms and disease severity in rheumatoid arthritis: interaction with their plasma levels. Genes Immun $2001 ; 2: 222-8$.

12 Kaijzel EL, van Dongen H, Bakker AM, Breedveld FC, Huizinga TW, Verweii CL. Relationship of polymorphisms of the Interleukin-1 gene cluster to occurrence and severity of rheumatoid arthritis. Tissue Antigens 2002; 59:122-6

13 Sugiura $Y$, Niimi T, Sato S, Yoshinouchi T, Banno S, Naniwa T, et al Transforming growth factor $\beta 1$ gene polymorphism in rheumatoid arthritis. Ann Rheum Dis 2002;61:826-8.

14 Pokorny V, Chau J, Wu L, Yeoman S, Black P, McQueen F, McLean L. Transforming growth factor $\beta 1$ gene (HSTGFB1) nucleotide T869C (codon 10) polymorphism is not associated with prevalence or severity of rheumatoid arthritis in a Caucasian population. Ann Rheum Dis 2003:62:907-8.

15 Fava R, Olsen N, Keski-Oja J, Moses H, Pincus T. Active and latent forms of transforming growth factor beta activity in synovial effusions. J Exp Med $1989 ; 169: 291-6$

16 Brennan FM, Chantry D, Turner M, Foxwell B, Maini R, Feldmann M. Detection of transforming growth factor-beta in rheumatoid arthritis synovia tissue: lack of effect on spontaneous cytokine production in joint cell cultures. Clin Exp Immunol 1990;81:278-85.

17 Taketazu F, Kato M, Gobl A, Ichijo H, ten Dijke P, Itoh J, et al. Enhanced expression of transforming growth factor-betas and transforming growth factor-beta type II receptor in the synovial tissues of patients with rheumatoid arthritis. Lab Invest 1994;70:620-30.

18 Blobe GC, Schiemann WP, Lodish HF. Role of transforming growth factor beta in human disease. N Engl J Med 2000;342:1350-8.

19 Grainger DJ, Heathcote K, Chiano M, Snieder H, Kemp PR, Metcalfe JC, et al Genetic control of the circulating concentration of transforming growth factor type betal. Hum Mol Genet 1999;8:93-7.

20 Yokota M, Ichihara S, Lin TL, Nakashima N, Yamada Y. Association of a $\mathrm{T} 29 \rightarrow$ C polymorphism of the transforming growth factor-betal gene with genetic susceptibility to myocardial infarction in Japanese. Circulation 2000;101:2783-7.

21 Crilly A, Hamilton J, Clark CJ, Jardine A, Madhok R. Analysis of transforming growth factor betal gene polymorphisms in patients with systemic sclerosis. Ann Rheum Dis 2002;61:678-81
22 Wong TY, Poon P, Chow KM, Szeto CC, Cheung MK, Li PK. Association of transforming growth factor-beta (TGF-beta) T869C (Leu 1OPro) gene polymorphisms with type 2 diabetic nephropathy in Chinese. Kidney Int 2003:63:1831-5.

23 Dunning AM, Ellis PD, McBride S, Kirschenlohr HL, Healey CS, Kemp PR, et al. Transforming growth factor betal signal peptide variant increases secretion in vitro and is associated with increased incidence of invasive breast cancer. Cancer Res 2003:63:2610-15.

24 Wu L, Chau J, Young RP, Pokorny V, Mills GD, Hopkins R, McLean L, Black PN. Transforming growth factor-beta(1) genotype and susceptibility to chronic obstructive pulmonary disease. Thorax 2004;59:126-9.

25 Li Z, Habuchi T, Tsuchiya N, Mitsumori K, Wang L, Ohyama C, et al. Increased risk of prostate cancer and benign prostatic hyperplasia associated with transforming growth factor-beta 1 gene polymorphism at codon 10 . Carcinogenesis 2004;25:237-40.

26 Silverman ES, Palmer U, Subramaniam V, Hallock A, Mathew S, Vallone J et al. Transforming growth factor-betal promoter polymorphism C-509T is associated with asthma. Am J Respir Crit Care Med 2004; 169:214-19.

27 Yamada Y, Miyauchi A, Goto J, Takagi Y, Okuizumi H, Kanematsu M, et al. Association of a polymorphism of the transforming growth factor-beta 1 gene with genetic susceptibility to osteoporosis in postmenopausal Japanese women. J Bone Miner Res 1998;13:1569-76.

28 Hinke V, Seck T, Clanget C, Scheidt-Nave C, Ziegler R, Pfeilschifter J. Association of transforming growth factor-betal (TGFbetal) T29 $\rightarrow \mathrm{C}$ gene polymorphism with bone mineral density (BMD), changes in BMD, and serum concentrations of TGF-betal in a population-based sample of postmenopausal German women. Calcif Tissue Int 2001;69:315-20.

29 Arkwright PD, Laurie S, Super M, Pravica V, Schwarz MJ, Webb AK, Hutchinson IV. TGF-beta(1) genotype and accelerated decline in lung function of patients with cystic fibrosis. Thorax 2000;55:459-62.

30 Arnett FC, Edworthy SM, Bloch DA, et al. The American Rheumatism Association 1987 revised criteria for the classification of rheumatoid arthritis. Arthritis Rheum 1988;31:315-24.

31 Larsen A, Dale K, Eck M. Radiographic evaluation of rheumatoid arthritis and related conditions by standard reference films. Acta Radiol (Stockh) 1977; 18:481-91.

32 Fries JF, Spitz P, Kraines RG, Holman HR. Measurement of patient outcome in arthritis. Arthritis Rheum 1980;23:137-45

33 Perrey C, Turner SJ, Pravica V, Howell WM, Hutchinson IV. ARMS-PCR methodologies to determine IL-10, TNF- $\alpha$, TNF- $\beta$ and TGF $\beta 1$ gene polymorphisms. Transplant Immunol 1999;7:127-8.

34 Hassell AB, Davis MJ, Fowler PD, Clarke S, Fisher J, Shadforth MF, The relationship between serial measures of disease activity and outcome in rheumatoid arthritis, et al. Q J Med 1993:86:601-7.

35 Plant MJ, Williams AL, O'Sullivan MM, Lewis PA, Coles EC, Jessop JD. Relationship between time-integrated $C$-reactive protein levels and radiologic progression in patients with rheumatoid arthritis. Arthritis Rheum 2000;43:1473-7.

36 Dick IM, Devine A, Li S, Dhaliwal SS, Prince RL. The T869C TGF beta polymorphism is associated with fracture, bone mineral density, and calcaneal quantitative ultrasound in elderly women. Bone 2003;33:335-41.

37 Lau EM, Wong SY, Li M, Ma CH, Lim PL, Woo J. Osteoporosis and transforming growth factor-beta-1 gene polymorphism in Chinese men and women. J Bone Miner Metab 2004;22:148-52.

38 Ziv E, Kahn A, Cauley J, Morin P, Saiz R, Browner W. No association between the TGF-beta 1 Leu1OPro polymorphism and osteoporosis among white women in the United States. Am J Med 2003;1 14:227-31.

39 Chehata JC, Hassell AB, Clarke SA, Mattey DL, Jones MA, Jones PW, Dawes PT. Mortality in rheumatoid arthritis: Relationship to single and composite measures of disease activity. Rheumatology 2001:40:447-52.

40 Kim YJ, Lee HS, Im JP, Min BH, Kim HD, Jeong JB, et al. Association of transforming growth factor-betal gene polymorphisms with a hepatocellular carcinoma risk in patients with chronic hepatitis B virus infection. Exp Mol Med 2003:35:196-202.

41 Ziv E, Cauley J, Morin PA, Saiz R, Browner WS. Association between the $\mathrm{T} 29 \rightarrow C$ polymorphism in the transforming growth factor betal gene and breast cancer among elderly white women: The Study of Osteoporotic Fractures. JAMA 2001;285:2859-63.

42 Hishida A, Iwata H, Hamajima N, Matsuo K, Mizutani M, Iwase T, et al Transforming growth factor B1 T29 Colymorphism and breast cancer risk in Japanese women. Breast Cancer 2003;10:63-9.

43 Krippl P, Langsenlehner U, Renner W, Yazdani-Biuki B, Wolf G, Wascher TC, et al. The LIOP polymorphism of the transforming growth factor-beta 1 gene is not associated with breast cancer risk. Cancer Lett 2003:201:181-4

44 Le Marchand L, Haiman CA, van den Berg D, Wilkens LR, Kolonel LN Henderson BE. T29C polymorphism in the transforming growth factor betal gene and postmenopausal breast cancer risk: the Multiethnic Cohort Study. Cancer Epidemiol Biomarkers Prev 2004;13:412-5.

45 Shu XO, Gao YT, Cai Q, Pierce L, Cai H, Ruan ZX, et al. Genetic polymorphisms in the TGF-beta 1 gene and breast cancer survival: a report from the Shanghai Breast Cancer Study. Cancer Res 2004;64:836-9. 